\title{
Seroprevalence of Ovine Brucellosis in the Western, Middle and Southern Areas of Libya
}

\author{
M. Abo Rokia ${ }^{1}$ L. Bakar ${ }^{2}$, A. A. Abdalla ${ }^{2}$ \\ ${ }^{1}$ Faculty of Agriculture and Veterinary Science, Tarhouna, AL Mergeb University and ${ }^{2}$ Faculty of \\ Veterinary Medicine and Agriculture Science, El-Zawia University.
}

In this study a total of 2230 sheep (one-three years of age) were serologically surveyed in three selected areas in Libya (Western, Middle and Southern areas) to specify foci of infection and determination of the prevalence of ovine brucellosis using Rose Bengal Plate Test and Rivanol test. Prevalence of brucellosis in this study revealed $4 \%, 0 \%$ and $0 \%$, respectively. Only the western area showed positive cases, while the Middle and Southern areas showed no serological evidence of brucella infection.

Brucellosis is one of the major serious worldwide diseases caused by facultative intracellular bacteria of the genus Brucella (Cheers, 1984). Thus, the early detection of Brucella infection in a herd is of at most importance for the successful control and elimination of one of the major problems that considered being a predisposing factor of infertility and sterility, along with the possible transmission of infection to man (FAO, WHO 1986 and Wasseif, 1992).

Migratory sheep and goats especially those grazing after cattle constitute a major risk and can make serious breakdowns in the control program (Fawzia Abo El-Khirat, 2010). These small ruminants present a major risk to dairy cattle herds as well as to intensively managed herds that are fed on fodder harvested from sheep and goats infected areas.

Control of brucellosis in animals is still considered a difficult task due to the contagious nature of the disease, wide host range, latency as well as difficulty to detect all infected cases at all stages of the disease (Lior et al., 2009).

Brucellosis causes severe economic losses due to abortion, decrease of milk yield, breeding troubles, infertility and the high costs of diagnosis and control measures (Xavier et al., 2009).

Control of brucellosis is an exhaustive difficult task, Hosein et al., (2002) because of the wide host range including large and small ruminants, pets, swine, equine, rodents, wild ruminants, Alton, (1990). This complicates the control of such disease that also needs considerable long time period, high cost and collaboration of all efforts between animal breeders and the governments.

The present work was carried out to investigate the prevalence of ovine brucellosis in the Western, Middle and Southern areas of Libya.

\section{Material and methods}

Animals. A total of 2230 sheep (one-three years of age) were employed in this study to determine the prevalence of brucellosis in the Western, Middle and Southern areas of Libya.

Blood serum samples. A total of 2230 sheep (one-three years of age) were employed in this study to determine the prevalence of brucellosis.

\section{Antigens}

Rose-Bengal antigen. It is an eight percent cells of $\mathrm{Br}$. abortus strain 99 stained with Rose Bengal in lactate buffer ( $\mathrm{pH} 3.65 \pm 0.05)$. It was obtained from institute Pourquier,England.

Rivanol antigen. It is a four percent cells of $B r$. abortus strain 99 stained with brilliant green and crystal violet in citrate-phosphate buffer (pH5.86.2). Rivanol antigen and Rivanol solution(2ethoxy 6,9-diaminoacridine lactate $1 \% \mathrm{w} / \mathrm{v}$ ) were obtained from institute Pourquier, England. Collection of blood samples. Blood serum samples of 2230 sheep (Table 1) were collected without anticoagulant by vein puncture where skin over the jugular vein was prepared by clipping, defatted by rubbing with a swab soaked in alcohol, then disinfected by tincture of iodine. About $10 \mathrm{ml}$ of blood were aseptically drawn from jugular vein into a sterile evacuated test tube. The test tubes were left at room temperature in a sloping position to allow clotting for 2 hours. The collected samples were labeled, identified and transferred to the laboratory, where they held in refrigerator till the next day, to give chance of serum to separate .the serum was siphoned by Pasteur pipette and centrifugation at 2800 r.p.m for 20 minutes, the clean serum stored in epindwarf tubes and kept in at $-20^{\circ} \mathrm{C}$ until used. 
Table (1): Blood samples collected from 2230 sheep in the Western, Middle and Southern areas of Libya.

\begin{tabular}{ll}
\hline Area & No. of samples \\
\hline Western area & 1487 \\
Middle area & 360 \\
Southern area & 383 \\
Total & 2230 \\
\hline
\end{tabular}

\section{Serological examination}

Rose- Bengal plate test (RBPT). The test was carried out according to Morgan et al., (1978). The sera to be tasted and antigen were brought at room temperature before testing. One drop $(0.03$ $\mathrm{ml})$ of the tasted serum was placed alongside the antigen. The antigen and serum were thoroughly mixed and reading was done within 4 minutes rocking period. Known positive and negative sera were include as control

Results were recorded as follows:

$(-)=$ Negative $=$ no agglutination

$(+)=$ Positive $=$ any degree of agglutination

Rivanol test (Riv. T). The test was carried out according to Alton et al., (1988) as follows:

- A quantity of $0.4 \mathrm{ml}$ Rivanol solution was placed in Wassermann tube, to which an equal amount of serum to be tasted was added. The tube was shaken; a heavy yellow precipitate was formed as soon as the serum and Rivanol solution come in contact

- The tube was allowed to stand at least 10 minutes and not more than one hour

- Tubes were then centrifuged for 10 minutes at $3000 \mathrm{rpm}$

- Using special pipette $0.08,0.04,0.02,0.01$ and $0.005 \mathrm{ml}$ of the yellow supernatant solution were delivered in the center of squares of a glass plate. This gives dilutions of serum as follows $1 / 25$, $1 / 100,1 / 200$ and $1 / 400$, respectively. One drop $(0.03 \mathrm{ml})$ of Rivanol antigen was added to each of the serum quantity in the squares

- Mixing was done thoroughly with a stirrer, starting with the $0.005 \mathrm{ml}$ drop and ending with $0.08 \mathrm{ml}$ drop

- The plate was rotated in a circular motion for 4 times, and then incubated under cover for 6 minutes to minimize evaporation.

- After another 6 minutes, the plates were rotated again and the test read according to the degree of agglutination as follows:

Negative reaction homogenous mixture without any evidence of agglutination

Incomplete reaction: Intermediate of agglutination
Complete reaction: Nearly complete agglutination; the test was interpreted as positive when any degree of agglutination observed in the original dilution.

\section{Results and discussion}

\section{Results of serological examination revealed:}

1-Western area: A total of $90(4 \%)$ were positive reactors.

2-Middle area: No. of reactors $0(0 \%)$.

3- Southern area: No of reactors $0(0 \%)$.

An animal was classified as positive when both tests were positive.

Bovine brucellosis still constitutes a serious problem to live- stock breeders in many countries of the world due to its great economic impact and public health hazard. Losses because are mainly due to abortion, decrease in milk production, infertility troubles, slaughtering of positive cases and cost of control programs (Soliman, 1998).

Serological diagnosis is still the principal tool for detection of brucella-infected animals. Successful control of the disease depends largely on successful diagnosis which in turn is based upon the use of efficient serological tests for picking up positive cases (Hosein et al., 2002).

Sheep and goats are classically the natural hosts of brucella melitensis. Such definition relates to the fact that Brucella melitensis preferably causes abortion in goats and sheep.

In this study a total of 2230 sheep were serologically surveyed in three selected areas in Libya (Western, Middle and Southern areas) to specify foci of infection using Rose Bengal Plate Test and Rivanol test (Figure 2). Prevalence of brucellosis in this study revealed $4 \%, 0 \%$ and $0 \%$, respectively. Only the western area showed positive cases, while the Middle and Southern areas showed no serological evidence of brucella infection. This may be attributed to the fact that sheep in the western area are in true contact with animals of neighboring infected countries.

A prevalence of $(4.36 \%)$ was recorded by Fawzia Abo El-Khirat (2010) in El Ogilat in the western area using Rose Bengal Plate Test on 720 sheep serum samples. Moreover Sassi, (1998) reported a prevalence of $(4.5 \%)$ in 420 ewes using Rose Bengal Plate Test and Tube agglutination Test in Tripoli.

The discrepancy between the various studies and the present study could be attributed to a multitude factors of which the different tests and techniques applied, different regions or areas of investigation, number of examined animals, 
management and the rate of exposure in certain years.

An important factor responsible for the spreading of brucellosis in Libya is the uncontrolled importation of small ruminants from some countries where brucellosis is still prevalent (EL-Gibaly, 1969; Barsoum, 1984; Wasseif, 1992).

Concerning the relatively moderate or slightly high prevalence of Brucella reactor sheep in the western area (4\%), It would be mentioned however that, sheep and goats are kept in big flocks and where farmers and shepherds keep aborted, pregnant and non pregnant animals in the same flock, which can give higher chance for other sheep and goats to catch Brucella infection (Lamyaa, 2005).

The present study indicated the importance of application of continuous surveys for detection of brucella infection among all animal species due to the economic losses of the disease as well as the public health significance of brucellosis.

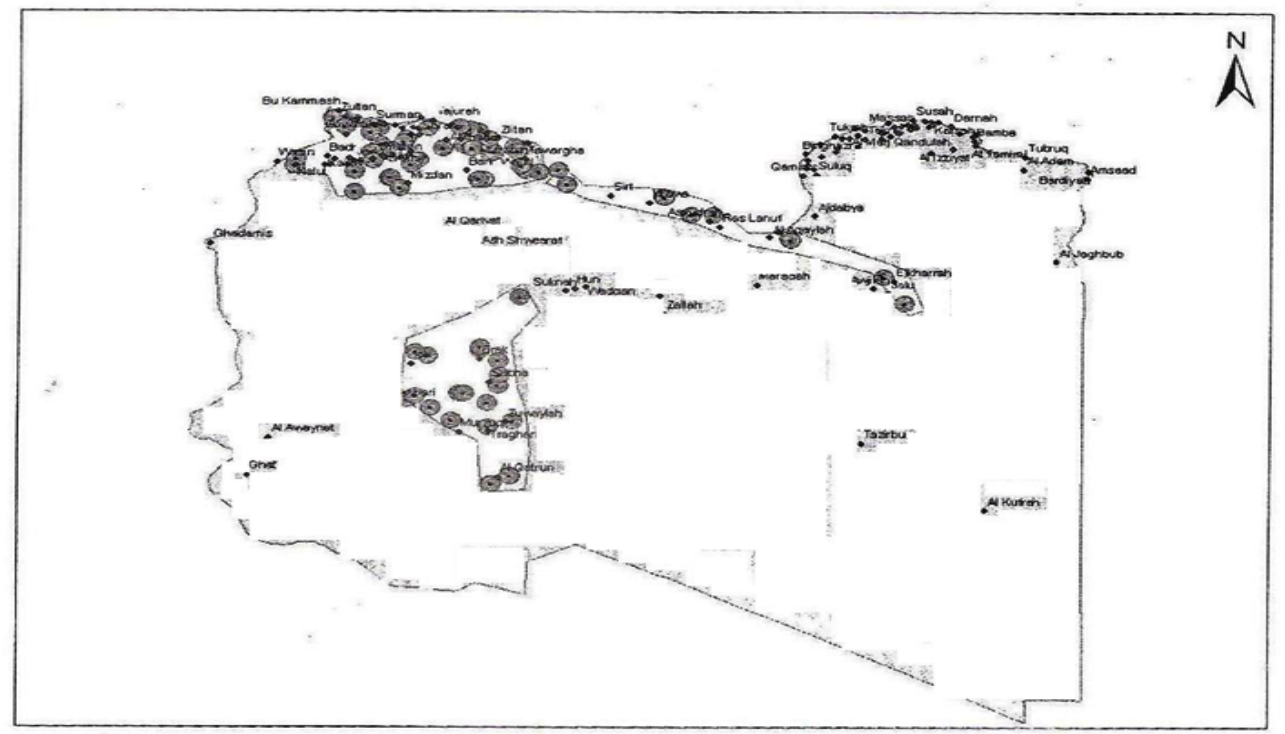

Fig. (1): Distribution of sheep population in Libya.

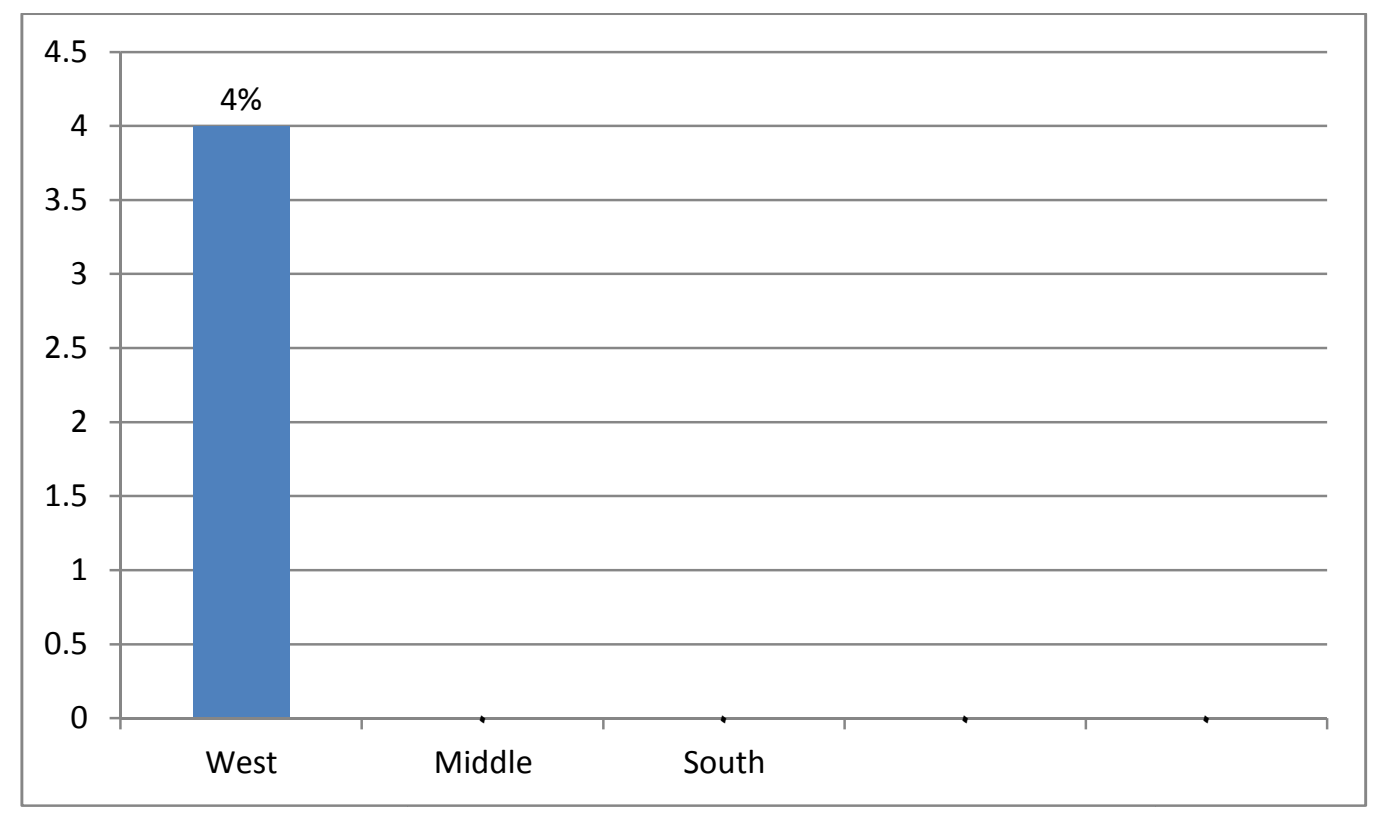

Fig. (2). The prevalence of Brucellosis in the Western, Middle and Southern areas of Libya. 


\section{References}

Alton, G. G.; Jones, L. M; Angus, R. D. and Verger, J. M. (1988): Techniques for the Brucellosis Laboratory. INRA Publications, Paris, France.

Alton, G. G. (1990): Brucella melitensis, 1887 to 1987 cited in Animal Brucellosis by K.Nielsen and J.R.Dun can. CRC Pren Boston.

Barsoum, S. A. (1984): Studies on brucellosis in farm animals in Egypt.Ph. D. Thesis, (Department of Animal and Fish diseases), Fac of Vet Med Cairo University.

Cheers, c. (1984): Pathogenesis and cellular immunity in experimental murine brucellosis. Dev Biol Stand, 56: 237246.

El-Gibaly, S.M. (1969): Studies on brucellosis in dairy animals in UAR.M.V.Sc. Thesis, Fac. Of Vet.Med., Cairo University.

FAO/WHO (1986): FAO/WHO Expert Committee on Brucellosis $6^{\text {th }}$ Report,WHO. Techn. Rep. Series, 740: 101.

Fawzia Abo El-Khirat (2010): Prevalence of Ovine brucellosis in El-Ogilat, Libya. MVSC.biology,academy of higher studies ,Tripoli,Libya.

Hosein, H. I.; Dawood, F. Z. and El-Sheery, M. N. (2002): Evaluation of the policy of test and slaughter for control of brucellosis in Egypt.

Lamyaa , M . B . ( 2005 ) : Public health importance of brucellosis in Menofia Governorate. Ph. D. Thesis, (Zoonosis) Fac Of Vet Med, Moshtohor. Zagazig Univ.

Lior, D.; Sergi, D. ; Lucio, P. and Nimord, R. (2000): Long standing reglected sacroiliitis with remarked sacroiliac degenerative changes as a result of Brucella species infection The Spine Journal, 9: 1-4.

Morgan, W. J. B.; Mackinnon, D. J.; Gill, K. P. W.;Gower,S. G. M. and Norris, P. I. W. (1978): Standard laboratory techniques for the diagnosis of brucellosis. Report Series No. I, Weybridge Cent. Vet Lab, England.

Sassi, M. F. (1998): Seroepidemiological study on grucellosis in animals and man.Beni Suef Med Res, 8(2): 213- 218 .

Soliman, S. A. (1998): Studies on brucellosis in farm animals with reference to public health importance in Suez Canal district.Ph. D. Thesis, Fac Vet Med, Suez Canal Univ Techniques for the Brucellosis Laboratory. INRA, Puplication, Paris, ISEN, France.

Wasseif, S. M. (1992): Brucellosis in Sharkia Governoratean epidemiological study. Egypt. J Occup Med, 10: 247 258.

Xavier, M. T. N.; Paixao, T. A. F. P.; Lage, A. P. and Santos, R. L. (2009): Pathological, immunohistochemical and bacteriological study of tissue and milk of cows and feuses experimentally infected with Brucella abortus: J cop Path, 140: 149-197. 